\title{
Hirsutism, CTCAE
}

National Cancer Institute

\section{Source}

National Cancer Institute. Hirsutism, CT CAE. NCI Thesaurus. Code C143547.

A disorder characterized by the presence of excess hair growth in women in anatomic sites where growth is considered to be a secondary male characteristic and under androgen control (beard, moustache, chest, abdomen). 